\title{
La paz interior y el testamento. El testar como acto liberador. Siglo XVII
}

\author{
Astrid Guiovanna Rojas Vargas \\ Universidad Nacional de Colombia \\ arv_odiseo@yahoo.es
}

\begin{abstract}
Resumen
El artículo se aproxima al testamento colonial, describiéndolo y analizando su estructura interna y, posteriormente, observando el acto de testar, no solo como una convención notarial, sino como un acto religioso, última oportunidad de salvar el alma para la vida eterna y de liberar la conciencia del peso de la vida en el mundo, lo cual muestra que testar era un acto liberador. El trabajo se realizó mediante la combinación de métodos cuantitativos y cualitativos, con una muestra de 50 testamentos registrados en Santafé durante el siglo XVII. El uso de fuentes complementarias permitió una mejor comprensión de la forma de morir en esta época y las razones del acto de testar.

Palabras clave: TESTAMENTO, RELIGIOSIDAD, IGLESIA CATÓLICA, SANTAFÉ, SIGLO XVII.
\end{abstract}

\begin{abstract}
This article brings us closer to understanding the nature of the colonial will, describing it and analyzing its internal structure; the study also examines the process of creating the will itself, not only as a notarial convention, but also as a religious act, the final opportunity to save one's soul for eternity and liberate one's conscience of life's earthly burdens, all of which reflect that the making of a will itself was a liberating act. The research for this work combines qualitative and quantitative methods, with a sample of 50 registered wills from seventeenth-century Santafé. The use of complementary sources leads to an improved understanding of the nature of dying during the period and the reasons behind the making of a will.

Key words: TESTAMENT, RELIGIOUSNESS, CATHOLIC CHURCH, SANTAFÉ, $17^{\mathrm{TH}}$ CENTURY.
\end{abstract}


Sin duda dio a entender que el manjar más sazonado de su Divina Mesa, y más gustoso al paladar de su amor, es una alma, que redimida con su preciosísima Sangre, se halla débil pececillo en un océano de amarguras a la hora de la muerte, ha peligro de que la pesquen los engaños de Satanás, y cogida la suave red del santo aviso de quien la asiste, escapa de las infernales candelas, y se acoge para Dios, que la crió para el Cielo ${ }^{1}$.

\section{Introducción ${ }^{2}$}

Los estudios sobre la historia cultural de diferentes períodos históricos, día a día avanzan respecto a factores tales como la vida social, política o cotidiana; siguiendo este orden de ideas, el presente trabajo busca aportar nuevas luces sobre uno de esos aspectos culturales de la historia colombiana durante el período colonial: la religiosidad popular ante la muerte en el siglo XVII, en la ciudad de Santafé; la razón por la cual se ha escogido una historia de la muerte o sobre la muerte, es que ella, como situación biológica indisolublemente ligada a la vida, es generadora de actitudes y comportamientos que, marcados por la situación histórica particular dentro de la que se presentan, forman parte de la definición y tipificación de un sistema cultural.

Este artículo busca, en la medida de lo posible y dadas las limitaciones de espacio, realizar una aproximación al testamento y al acto de testar, definiéndolos como fundamentales dentro del sistema cultural del Antiguo Régimen, en la medida que son actos más religiosos que notariales, signos de la religiosidad de los individuos y de la forma como los hombres -en este caso, los habitantes de la Santafé del siglo XVII- enfrentaron el pasaje de la muerte, seguro e imposible de rehuir. Su observación ha sido posible gracias a las informaciones indirectas que estos hombres nos proporcionaron sin saberlo y a las huellas que nos han dejado leer en sus testamentos, actos finales de su vida; observándolos detenidamente, se constata que lo expresado en estos documentos no es más que el reflejo inconsciente de la angustia provocada por la conciencia de la finitud de su vida terrena y la incertidumbre sobre su vida futura; de esta suerte, testar se convirtió en un acto liberador para estos hombres y, a la vez, tornó al testamento en un documento religioso, más que notarial, que consignaba las esperanzas y expectativas frente al

\footnotetext{
${ }^{1}$ Baltasar Bosch de Centellas y Cardona, Prácticas de visitar a los enfermos y ayudar a bien morir, 4 ed. (Madrid: Imprenta de Gregorio Hermosilla, 1722), 3.

2 Esta comunicación recoge conclusiones extraídas de mi trabajo monográfico “Testamentos santafereños del siglo XVII. ¿Reflejos de una sociedad barroca?”.
} 
más allá, y además les permitía liberarse de secretos y sentimientos mantenidos ocultos durante la vida.

También, la fuente testamentaria brinda a los investigadores de nuestro tiempo la posibilidad de aproximarnos al mundo de la religiosidad popular ${ }^{3}$ de los individuos del Antiguo Régimen, sacando a la luz buena parte de sus elementos visibles a través de índices cuantificables, huella de algo más profundo coincidente con una

\footnotetext{
${ }^{3}$ Religiosidad popular no es sinónimo de religiosidad de las clases inferiores o un tipo de experiencia religiosa inferior o supersticiosa, respecto a la ortodoxia dogmática y sus lineamientos generales en cuanto a creencias y cultos que enmarcan la religión oficial. La religión abarca tanto estas experiencias religiosas uniformes y elaboradas como expresiones más cotidianas, ingenuas, milagrosas e intimistas; ambos tipos de expresión constituyen símbolos culturales colectivos y representaciones mentales individuales. Estos símbolos y representaciones configuran modelos y estrategias cognitivas relativas a la significación dada a la vida y a la muerte, y se convierten en creencias que no son equiparables simplemente con el dogma, ya que tienen componentes tanto intelectuales como emocionales. La religiosidad oficial y la popular se equiparan, entonces, en tanto son sistemas coherentes y consistentes de creencias enfocados a resolver dudas y problemas relativos a la existencia, la vida y la muerte. Durante el Antiguo Régimen, la religiosidad oficial estaba representada por las elaboraciones mentales reflexivas, "imaginación reflexiva", de una élite de teólogos que establecen las claves interpretativas del dogma y poseen el poder de su transmisión y de su producción mediante el manejo de la escritura, la cual convierte esta producción en conocimiento trascendental; por otro lado, la religiosidad popular hace referencia a las elaboraciones mentales populares, "imaginación popular", que no se acercan tanto a la reflexión pero sí se cargan fuertemente del sentido común, conferido por el conocimiento popular adquirido por medio de la experiencia sensible de la vida y de sus problemas concretos (agricultura, curanderismo, etc.), de las creencias religiosas (milagros, cultos, devociones) y remite a manifestaciones rituales propias y espontáneas del grueso de la población, que equilibran su salud mental y espiritual al mantener y alimentar sus esperanzas $\mathrm{y}$ anhelos $\mathrm{y}$ reafirmar sus convicciones. La religiosidad popular es, finalmente, una forma de asumir todos los aspectos de la vida y a la vida misma, por parte de todas las clases sociales. Ya se trate de reyes, arzobispos, panaderos o lavanderas, todos compartían creencias a las que reaccionaban de manera tanto emocional como reflexiva. "A diferencia del criterio de racionalidad en teología, constituido en la aceptación de los argumentos que más inteligibles y eficaces resultan para resolver problemas de ideación, el modo cognitivo popular, al ser sus problemas por concreción eternos, no los hace desaparecer, sino que aprende a vivir con ellos. Es, pues, una forma de tratar con los problemas; de ahí que algunas creencias o ritos puedan parecer elementales o primitivos cuando, en realidad, lo único que ocurre es que no captamos la coherencia interna de su simbolismo implícito". María de Jesús Buxó i Rey, coord., La religiosidad popular, vol. 2, Vida y muerte: la imaginación religiosa (Barcelona: Anthropos, 1989), 3.
} 
situación histórica que envuelve todos los aspectos de la vida y que se sustenta en su propio ethos cultural $^{4}$ y responde a sus exigencias vitales.

Este artículo se escribió con información obtenida de mi trabajo monográfico Testamentos santafereños del siglo XVII ¿Reflejos de una sociedad barroca? Se recurrió a los testamentos consignados en el Archivo General de la Nación (AGN), en la Sección Notarías. Se revisaron cincuenta testamentos de los años comprendidos entre 1600 y 1699 , presentes en la Notaría 1; a manera de complemento, se consultaron dos documentos impresos que se encuentran en la Biblioteca Nacional de Colombia, que tratan acerca de temas relacionados con el tema central de esta presentación y que, cotejados con la información obtenida de los testamentos, permitieron llegar a las siguientes conclusiones con respecto a la fuente testamentaria.

\section{La paz interior y el testamento. El testar como acto liberador}

En la sociedad neogranadina, al igual que en otras sociedades cristianas católicas durante el Antiguo Régimen, el elemento religioso era el eje central alrededor del cual se articulaban la vida cotidiana y las manifestaciones civiles y oficiales, así como las actuaciones colectivas y particulares. La religión se constituía en el elemento esencial y vertebrador ${ }^{6}$ de la cultura y de las mentalidades colectivas. Desde esta perspectiva, se hace realmente importante conocer la actitud del hombre ante la muerte, ya que, si no el fin último, esta sí constituye la separación de la materia y el espíritu, y significa además el desprendimiento de todos lo bienes, vivencias y afectos acumulados durante la vida terrena.

El amor por todas estas cosas generaba una gran ansiedad y angustia por la hora de la muerte. Esta pasión desenfrenada por la vida y sus riquezas, llamada por $\mathrm{Ph}$. Àries, avaritia ${ }^{7}$, exponía al cristiano a la condenación eterna. La Iglesia ofrecía una solución que permitía salvar los bienes eternos y rehabilitar el uso de los bienes temporales durante la vida, con lo que la avaritia se justificaba retroactivamente ${ }^{8}$ mediante un acto último de arrepentimiento y contrición, que permitía a la vez alcanzar la gloria eterna; la herramienta fundamental para alcanzar este preciado objetivo era el testamento.

\footnotetext{
${ }^{4}$ Ethos cultural es una abstracción teórica del tono, el carácter y la calidad de vida de un pueblo, representados en significaciones históricamente creadas, en su mundo cultural y en la forma global como es percibido el orden. Geertz Clifford, La interpretación de las culturas (Barcelona: Gedisa, 1995), 89.

${ }^{5}$ Durante el siglo XVII funcionaron en Santafé las notarías 1,2 y 3.

${ }^{6}$ Buxó, La religiosidad, 2:224.

${ }^{7}$ Philippe Àries, El hombre ante la muerte (Madrid: Taurus, 1984), 165.

${ }^{8}$ Ibídem.
} 
Aquí se ha de advertir cuánto se engañan los que aterrados con el temor de la muerte rehúsan el hacer testamento, y aun tienen horror de que en ello se les hable, como si los decretos de nuestro soberano Dios dependiesen de los hombres, o su Divina Majestad fuese variable, como los hombres lo son. Sepan, pues, los tales, que el mismo Señor supremo tiene constituidos los términos y el fin de vida de cada uno, de cuyo fin y término no puede pasar ni un instante: verdad Católica, que hallamos al capítulo 14 de Job: Breves dies hominis sunt, numeres nunsium eius apud te est: constituiste terminos eius, qui proeteriri non poterant $^{9}$; y así la muerte no ha de seguir según su opinión perversa de que ellos hagan testamento. Y si los que hubieren hecho su testamento sanaran después de la enfermedad, no habrá nada perdido, antes deben quedar más consolados [...] han hecho un acto heroico de humildad y de resignación en la voluntad de Dios, que por ventura, por haber visto ab eterno tales méritos, determinó en remuneración el que quedasen con perfecta salud, que sin estas buenas obras hubieran de morir [...] Nos conviene mucho una continua solicitud y cuidadoso desvelo, para asegurar acertado el último instante, diciéndonos el mismo Salvador del mundo: Estad prevenidos, porque no sabéis el día ni la hora: E stote parati: quia qua hora non putatis, filices hominis veniet [Luc. 12. vers. 40]. No suceda que cogidos de improviso sin esta precaución, de que el propio soberano juez nos avise, ni aun la menor excusa tengamos para nuestra defensa ${ }^{10}$.

A través de estos documentos, los bienes temporales eran rehabilitados y se obtenía la seguridad de los bienes eternos, gracias al espacio dado a los legados y obras pías que se disponían en ellos. Mediante estas últimas voluntades el hombre exorcizaba sus temores y multiplicaba sus esperanzas en un más allá venturoso, haciendo uso de estos medios que la Iglesia puso a su alcance, adoptando el ideal de renuncia como signo de arrepentimiento y conversión ${ }^{11}$.

El uso de los bienes temporales en los legados testamentarios legitimaba su uso en este mundo tanto para el testador mismo como para sus futuros herederos, incluida la Iglesia. Teniendo esto en cuenta, el acto de testar era, sin lugar a dudas, un deber de conciencia, pero también un acto religioso del que dependía la salvación eterna, dado su carácter de última oportunidad de bien morir $^{12}$; por esto último, el testar

\footnotetext{
9 “Ciertamente, sus días están determinados, y el número de sus meses está cerca de ti; le pusiste límites, de los cuales no pasará". Job, 14:5.

${ }^{10}$ Bosch, Prácticas de visitar, 30-32.

11 "Dice una regla del derecho: No se perdona el pecado si no se restituye lo hurtado [...] por medio de la confesión, y testamento se dispone como morir, restituya luego a sus próximos la fama, y bienes a que obligado estuviere; porque si parte su alma de esta vida agravada de semejantes cargos, irá condenada por una eternidad". Bosch, Prácticas de visitar, 32.

12 "Después que el enfermo haya procurado purificar su alma por medio de la Sagrada Confesión, se sigue el que trate de disponer de sus bienes; porque como se refiere de lo que el profeta Isaías dijo al Rey Exequías, es preciosa diligencia para morir bien: Dispone
} 
también se constituía en un acto liberador.

La Contrarreforma acentuó aún más el carácter pseudosacramental de este acto, pues convirtió en objeto pastoral la preparación para la muerte durante toda la vida, durante la salud y no solo cuando la enfermedad recordaba palpablemente la brevedad y la fragilidad de la vida material y de la vida eterna ante el pecado ${ }^{13}$. La muerte del prójimo era una ocasión perfecta para que la Iglesia recordara a sus fieles la importancia de esta preparación para la muerte durante toda la vida; las fuentes nos muestran que en la prédica sacerdotal, durante los sermones, se instaba a la feligresía a que no dejara la preparación para bien morir a los últimos momentos, ni que se limitara a dejar algunas órdenes dadas con este fin en el testamento; el sacerdote explicaba que el beneficio espiritual redundaría finalmente más en los albaceas que en el propio testador, puesto que los primeros se beneficiarían de las indulgencias propias del acto de cumplir con estas obras de caridad y amor cristiano, reduciendo los sufrimientos que podrían padecer en el Purgatorio o, incluso, evitando su paso y estadía por ese lugar; por otro lado, los testadores no conseguirían con estos actos más que reducir un poco el tiempo que debían permanecer en este lugar intermedio, pero no disminuir sus sufrimientos ni aliviar sus culpas, pues esto era algo que solo podía hacerse durante la vida mediante una estricta observación de los ideales de vida cristiana ${ }^{14}$.

domoni tue, quia moriréis tu, y non vives. [Is. 38-1]. Ordena y dispón de las cosas concernientes a tu casa, y hacienda, porque has de morir”. Bosch, Prácticas de visitar, 28.

13 "Pero hago juicio de que es mucho mejor hacer el testamento al principio de la enfermedad, y aun tenerlo hecho en sana salud, o cuando al principio de la enfermedad aún están despiertos los sentidos, y no entorpecidas las potencias. Mejor tratara cualquiera de lo que conduce a su salvación; y al contrario sucede cuando se agrava la enfermedad, de que nacen muchos inconvenientes; olvídanse algunas veces deudas y restituciones; resultan pleitos entre los mismos parientes y deudos; hácenles muchos testamentos nulos, interpretándose la última voluntad del testador con sentido siniestro”. Ibídem, 29.

${ }^{14}$ Un consejo da el autor al cristiano: que no negocie la vida en tiempo de la muerte, que, al morir, tenga ya hechas todas las diligencias de buen morir; "Esperar a la muerte a tratar negocios de perpetuar la vida, cosa es esa poco segura. Todos esos negocios los hacen en vida los cuerdos, de suerte que, cuando llegan a la muerte, ya no tienen que hacer ninguno"; "No en el vecino, ni en el pariente pongas el cumplimiento de lo que debes a Dios, si tu puedes hacerlo [...] de tu mano, de tu diligencia propia has de procurar cumplir con Dios, y con tu alma"; "Algunos entre los muertos se hallan como libres, pero otros, como esclavos en el Purgatorio, pues no han ganado cosa para sí, como los esclavos que trabajan mucho pero la ganancia no es para sí; en vida trabajaron por hacienda y por honra que dejaron para otros en este mundo y al llegar a la muerte ocuparon el tiempo en dar grandes mandas a otros, para sí, o nada, o unas pocas misas. Cuanto toca a la disposición de sus almas, lo remiten a los testamentarios, entran en el Purgatorio, allí penar, y más penar sin ganar para sí ni gracia, ni gloria, ni alivio; para los que estamos acá si mucho nos ganan las ánimas del Purgatorio". Diego de Baeza, Pbro. Sermones funerales catorce y de ánimas de Purgatorio 
El ánimo de estas predicaciones, que los clérigos extraían de sermonarios de uso obligatorio $^{15}$, no era desvirtuar el acto testamentario, pero sí acrecentar el miedo permanente a la condenación eterna, buscando que las gentes se mantuvieran dentro de los lineamientos de la moral cristiana y que vivieran teniendo en cuenta permanentemente el peligro que corrían al dejar todo para el último momento y no adoptar diariamente el ideal de vida cristiano. Claro está que no muchos testadores se preparaban para la muerte estando sanos, pero el solo hecho de que algunos lo hicieran indica que el temor a la muerte y al infierno estaba permanentemente presente y presidía las conductas colectivas dentro de una sociedad sacralizada tradicional, como la santafereña del siglo XVII. Además, pese a este tipo de prédicas de carácter funesto $\mathrm{y}$, en algunos casos, hasta macabro ${ }^{16}$, el común de las personas, incluido el clero, estaban seguras del poder salvífico del acto de testar y del testamento como última manifestación de sumisión y entrega a Dios.

Teniendo todo esto en cuenta, el acto de testar no se reserva exclusivamente a los ricos, quienes a primera vista tendrían una situación privilegiada para asegurar su salvación. La gente de recursos limitados, incluso los pobres de solemnidad, si bien debe reconocerse que en menor proporción, disponen de los pocos bienes que poseen y dan instrucciones sobre el destino de sus pequeños asuntos ${ }^{17}$, con el fin de velar por la salvación de su alma.

El testamento conjuga su carácter espiritual con el jurídico, lo que nos permite tener registro tanto de la confesión de fe, creencias y devociones del testador como de su vida profana y sus asuntos materiales, en la órbita del cumplimiento de su deber como cristiano, al poner su alma "en carrera de salvación" ", y también nos hace partícipes indirectos de su vida material, al mostrarnos de alguna forma a su comunidad, hablarnos de sus negocios, sus títulos, su trabajo, los cargos por él

siete, Sermón funeral III y IV (Valladolid: Marcos Pérez, 1645), IV: fol. 27v, fol. 28v, III: fol. $22 \mathrm{v}$.

${ }^{15}$ La institución eclesiástica reguló estrictamente, después del Concilio de Trento, los sermones que podían predicar los sacerdotes durante la misa; prohibió el que se improvisara con respecto a cualquier tema y promovió la publicación de sermonarios dedicados a diferentes temas, que los sacerdotes tenían que utilizar, ya sea leyéndolos durante la celebración o aprendiéndolos de memoria. Sobra decir que estos textos debían pasar por la censura y una estricta revisión antes de su publicación y difusión.

${ }^{16}$ El sermonario consultado tenía contenidos que iban desde lo nefasto que era aferrarse a la vida terrena, sin entender que el verdadero vivir estaba en la muerte y la unión a Cristo inherente a ella, hasta el carácter ejemplarizante de observar las fosas de los difuntos, llenas de despojos macilentos y pútridos, reflejos de la decadencia de la vida terrena y del gran error que constituía aferrarse a los bienes y deleites materiales.

${ }_{17}^{17}$ Ariès, El hombre ante la muerte, 168. Resaltado de la autora.

18 "Testamento de Melchor de Burgos" (1657), Archivo General de la Nación -en adelante, AGN- (Bogotá), Sección Notarías, Fondo Notaría 1, vol. 54, fols. 86-87v. 
ocupados y su pertenencia a una parroquia o a una hermandad o cofradía.

Otro punto importante al hablar de esta fuente documental es el debate sobre si verdaderamente el testamento es un acto personal o no es más que una serie de fórmulas estereotipadas usadas por los notarios indiscriminadamente en la redacción. Por mi parte, siguiendo a $\mathrm{M}$. Vovelle y a Ph. Ariès, y a pesar de la aparente rigidez de estos documentos, que tienen partes más o menos fijas, pienso que los múltiples tipos de redacción nos muestran un cierto grado de libertad que permite entrever el pensamiento del testador. Las sutiles diferencias, aunque no nos proporcionen confidencias tan intimistas e individuales como quisiéramos, nos dejan ver un cierto número de creencias y de fórmulas personales que dan pie al análisis. Los testimonios que nos brindan estos documentos permiten al historiador rastrear las creencias, la cultura y las mentalidades colectivas.

El testador expresa mediante este último acto la conciencia que tiene de sí mismo, sus temores y esperanzas, su futuro, su vida espiritual y la responsabilidad ante su propia alma y la de los suyos, y sus deberes para con sus deudos, y es por eso que afirma en el acto de testar la importancia que para él y para su sociedad toda tiene la última voluntad. Por todo esto, la finalidad del testamento no es solamente dar un destino a los bienes; a través de este documento el testador busca dejar constancia de las disposiciones que desea se cumplan acerca de su cuerpo fallecido y de su alma inmortal, con lo que espera alcanzar la salvación eterna y conjurar el miedo natural a la muerte y el otro miedo, más terrible, al juicio final y al más allá. Para cumplir este objetivo, declara su fe y creencias, su adscripción a la Santa Madre Iglesia de Roma ${ }^{19}$; demanda una infinidad de misas, novenarios y otros actos píos; declara también sus secretos, sus afectos, sus deudas y sus pecados, y, por último, enumera todo aquello material y terreno que ha poseído en vida y el destino final que debe dársele luego de su fallecimiento.

\section{Los testadores}

Tan importante como el testamento, que nos permite acercarnos a este mundo sacralizado, pleno de religiosidad, es aquel personaje que plasma una parte de sus creencias y pensamientos en el documento, pues sin los testadores no sería posible este estudio. Inicialmente, podemos determinar que el masculino es el sexo predominante en la muestra de 50 testamentos ${ }^{20}$, con 31 otorgantes sobre 20

\footnotetext{
19 "Testamento de Doña María Blanco" (1613), AGN, Sección Notarías, Fondo Notaría 1, vol. 33, fols. 359-361v.

${ }^{20}$ El total de testadores es de 51; esto se explica porque uno de los documentos es un testamento recíproco en el que se cuenta a cada cónyuge como individuo, a pesar de hacer sus disposiciones en un solo documento, y porque cada uno dicta algunas de manera
} 
testadoras. En cuanto al estado civil, son mayoría los casados una vez, con 20 testadores, cinco mujeres y 15 hombres; casados dos veces hay dos hombres y una mujer. El segundo estado civil más abundante es la viudez, con 16 casos, predominando esta vez las mujeres, con 10 viudas frente a seis hombres en el mismo estado; de viudos en más de una ocasión solo hay un caso de un hombre que enviudó dos veces. Finalmente, encontramos a los solteros: una mujer y un hombre.

Con respecto a la posición social y económica de los testadores, seis mujeres y cuatro hombres declaran tener título de don o de doña. Dentro del grupo femenino, dos aclaran ser españolas, una sevillana y la otra extremeña, las otras no dejan constancia de su origen o su raza, pero todas poseen bienes que les otorgan una posición económica suficiente para solicitar que se cumpla un buen número de disposiciones para la salvación de sus almas. En cuanto a los hombres, uno es un cacique indígena, otro es un mestre de campo holandés y los otros dos son españoles. Estos últimos ocupan posiciones en el gobierno de la Real Audiencia y ostentan una posición económica holgada que los deja disponer de un servicio fúnebre de calidad y una gran cantidad de misas, lo cual no es tanto índice de su religiosidad como de su posición social y económica.

El 38\% de los testadores declaran su profesión; de ellos, los estancieros, tres mujeres y dos hombres, conforman el $26,3 \%$, y el $36,8 \%$ se dedican a algún tipo de comercio, contándose aquí aquellos que simplemente se declaran "comerciantes", una tendera, un minero y dos prestamistas. Después, el 21\% tiene algún cargo oficial, como capitán de armas de Santafé, oidor de la Real Audiencia o gobernador, y, finalmente, otras profesiones, como mestre, maestro capellán, cacique y sargento, para el $15,7 \%$ restante. Las diferencias de riqueza de estas personas son bastante pronunciadas, siendo en general más adinerados aquellos que ostentan cargos oficiales. La persona que declara su profesión y tiene menos recursos es María Terranova, negra horra ${ }^{21}$ que se declara tendera.

Otra cuestión llamativa dentro de la muestra es la gran cantidad de testadores que no declaran su origen, constituyéndose en mayoría, con 24 personas (el $48 \%$ del total de la muestra), siendo igual el número de hombres que el de mujeres. Los siguen aquellos nacidos en España, tres mujeres y 13 hombres (el 32\%). Del Nuevo Reino de Granada son tres mujeres y cuatro hombres (el 14\%), y una mujer y dos hombres nacidos en la ciudad de Santafé. Para finalizar, aparece una mujer de origen africano y un hombre de origen holandés, que representan el $2 \%$ de la

diferenciada dentro del mismo. "Testamento recíproco de Catalina Delgado y Salvador Herrera" (1675), AGN, Sección Notarías, Fondo Notaría 1, vol. 114, fols. 479-481v.

${ }^{21}$ En la época, la palabra horra(o) con la que se designaba a algunos negros indicaba su condición de libres. 
muestra cada uno. Los religiosos se encuentran representados en un $12 \%$, con dos religiosas de la orden tercera de Santo Domingo, un novicio de San Francisco, el canónigo mayor de la iglesia Catedral y dos presbíteros.

El motivo más común que lleva al otorgante a testar es precisamente dejar arregladas las cosas terrenas y solucionar todos los asuntos mundanos que lo atan a esta vida, para dedicar la mayor parte del testamento a conseguir una eternidad bienaventurada mediante los descargos de conciencia, perfeccionando todos sus asuntos y consiguiendo el perdón de sus pecados en ese momento tan crucial. Algunos de los testamentos contienen fórmulas, como "poner mi alma en carrera de salvación”, que son índice de esta preocupación fundamental de la mentalidad de la época. 


\begin{tabular}{|c|c|c|c|c|c|c|c|}
\hline \multicolumn{8}{|c|}{ Tabla 1} \\
\hline \multicolumn{8}{|c|}{ Motivos para testar ${ }^{22}$} \\
\hline Sexo & $\begin{array}{l}\text { Edad muy } \\
\text { avanzada }\end{array}$ & $\begin{array}{l}\text { Viaje de } \\
\text { negocios }\end{array}$ & $\begin{array}{l}\text { Estar } \\
\text { apercibido } \\
\text { a la hora } \\
\text { de la } \\
\text { muerte }\end{array}$ & $\begin{array}{l}\text { Poner el } \\
\text { alma en } \\
\text { carrera de } \\
\text { salvación }\end{array}$ & $\begin{array}{l}\text { Que no } \\
\text { se lo } \\
\text { condene } \\
\text { al } \\
\text { infierno }\end{array}$ & $\begin{array}{l}\text { Estado de } \\
\text { salud }^{23}\end{array}$ & $\begin{array}{l}\text { Total } \\
\text { general }\end{array}$ \\
\hline Femenino & & & 1 & 1 & & 19 & 23 \\
\hline Masculino & 1 & 1 & & 3 & 1 & 21 & 31 \\
\hline Total & 1 & 1 & 1 & 4 & 1 & 40 & 48 \\
\hline
\end{tabular}

Fuente: AGN, Fondo Notarías, Notaría 1, vols. 24 -115; Notaría 2, vols. 13-17, 1600-1699.

\begin{tabular}{||c|l|l|l|l|l||}
\hline \multicolumn{9}{|c||}{ Tabla 2 } \\
\hline \multicolumn{1}{|c|}{ Sexo } & $\begin{array}{l}\text { Gravemente } \\
\text { enfermo }\end{array}$ & Enfermo & Convaleciente & Sano & $\begin{array}{l}\text { Total } \\
\text { general }\end{array}$ \\
\hline Femenino & 2 & 17 & & 2 & 21 \\
\hline Masculino & 2 & 18 & 1 & 4 & 25 \\
\hline Total & 4 & 35 & 1 & 6 & 46 \\
\hline
\end{tabular}

Fuente: AGN, Fondo Notarías, Notaría 1, vols. 24 -115; Notaría 2, vols. 13-17, 1600-1699.

${ }^{22}$ Algunos otorgantes exponen más de un motivo para formular sus testamentos.

${ }^{23}$ En solo dos casos los testadores expresan con claridad que la principal motivación para hacer el testamento es el estar gravemente enfermos; no obstante, en 39 testamentos, de un total de 50 que constituyeron la muestra, los testadores expresan sufrir algún tipo de enfermedad. Dentro de este ítem no se incluye a los testadores que se declaran sanos.

${ }^{24} \mathrm{El}$ resto de testadores (4) no manifiestan nada acerca de su estado de salud. 
De los testamentos que componen la muestra, tres no declaran ninguna motivación (6\%). Dentro del remanente, el motivo más corriente es el de encontrarse enfermos, expresado por el $83,3 \%$. Le sigue muy de lejos el de "poner mi alma en carrera de salvación", con $8,3 \%$, y los restantes motivos se comparten un $2 \%$. Cuarenta y seis (46) testadores mencionan su estado de salud, constituyéndose este en motivo para testar en 40 casos, es decir, en un $86,9 \%$ del total. De ellos se declaran gravemente enfermos el $8,6 \%{ }^{25}$, convalecientes el $2,1 \%$, simplemente enfermos el $76 \%$ y sanos el $13 \%$.

\section{Cláusulas devocionales}

La primera parte del testamento, en muchos casos más de la mitad del documento completo, está dedicada a las cláusulas devocionales, es decir, las invocaciones a Dios; la confirmación de fe y creencia en los preceptos que confiesa la Iglesia Católica $^{26}$; la invocación a los intercesores celestes; la declaración de sano juicio y voluntad $^{27}$; la encomendación del alma a Dios, "quien la creó, y a su hijo, quien la redimió a través de su pasión y muerte" ${ }^{28}$; y las cláusulas concernientes a la

${ }^{25}$ Estas cifras son sacadas del total de testadores que declaran su estado de salud y no del total de la muestra.

26 "Creyendo en todo aquello que tiene y confiesa la Santa Madre Iglesia de Roma". Testamento de Doña Isabel de Sea (1603), AGN, Sección Notarías, Fondo Notaría 1, vol. 7, fols. 172-173v. "Creyendo como creo [...] en todo aquello que cree y confiesa la Santa Madre Iglesia Romana”. Testamento de Doña María Blanco (1613), ibídem, vol. 33, fols. 359-361v. Recordemos que uno de los principales objetivos de la Contrarreforma fue consolidar el poder de la Iglesia Católica sobre su feligresía, así que uno de los preceptos doctrinales principales era la confianza infinita en esta madre bondadosa que acogía al pecador y lo ponía en contacto con El Creador.

${ }^{27}$ Esta condición es vista como un don de Dios. "Declaro mi entero sano juicio, memoria y voluntad que Dios, Nuestro Señor, es servido de me dar". Solo en siete (7) testamentos los otorgantes no realizan esta aclaración.

${ }^{28}$ Esta es una de las verdades de la Iglesia Católica que todos los testadores declaran profesar, pero que es de las menos entendidas, dada la confusión en casi todos los casos entre Dios padre y Jesucristo, su hijo, puesto que no se hace distinción entre uno y otro, figurando el primero como creador pero también como redentor. Se unen y se confunden así dos dogmas fundamentales del catolicismo, como son el de la creación y el de la redención. Algunos testadores hablan solo de Jesucristo como redentor, con lo que salvan este planteamiento, y otros pocos mencionan tanto al padre como al hijo, distinguiendo más o menos la obra de cada uno. La redacción más común de esta cláusula es "Mando mi ánima a Dios, Nuestro Señor, que la crió y redimió por su preciosísima sangre, y el cuerpo a la tierra de que fue formado". Los casos en los que se diferencian estos dogmas son los siguientes: Testamento de Doña María Blanco: "El cuerpo a la tierra y el alma a mi Señor Jesucristo, que la redimió con su preciosa sangre" (1613), AGN, Sección Notarías, Fondo Notaría 1, vol. 33, fols. 359-361v. Testamento de Pedro Mosquera de Tamayo: "Mando mi cuerpo a la tierra y mi alma a mi Señor Jesucristo, que la redimió con su preciosa sangre" 
mortaja y a la forma y lugar del enterramiento; el número de misas de cuerpo presente; del alma y de fundación, más novenarios, responsos, cabos de año, capellanías y mandas pías.

La parte devocional puede dividirse en dos, según su contenido: la primera sería la conformada por cláusulas de carácter declaratorio: invocación inicial, confirmación de fe, etc., y la segunda, la conformada por las de carácter decisorio: elección de mortaja, sepultura, de enterramiento, misas, sufragios, etc. Las declaratorias permanecen prácticamente inmodificadas en la longue dureé y nos permiten, por esa misma inercia, establecer el marco general de la religiosidad y sus permanencias a lo largo del tiempo. Las cláusulas decisorias, entre tanto, resultan más personales y susceptibles de cambio, lo cual nos acerca a las prácticas religiosas del momento de estudio, a sus creencias inmediatas, devociones, lugares favoritos para la práctica, etc.

En cuanto a las primeras, permanecen casi inalteradas a través del tiempo; las variaciones son realmente mínimas y no parecen seguir un patrón, pues mientras algunas cláusulas son expresadas con más sencillez a principios de siglo, otras, en cambio, son más complicadas durante estas mismas décadas, mientras que otras se enredan al finalizar el período cronológico estudiado.

Para no ir más lejos, en cuanto a la primera cláusula devocional, el encabezado, la fórmula más común en el siglo reza: "En el nombre de Dios, nuestro señor, amén"; no obstante, durante las primeras décadas se encuentran algunos encabezados huérfanos de contenido religioso ${ }^{29}$, hecho que no se repetirá más en el transcurso del siglo; desde luego, son una minoría. Para los demás testadores no hay ninguna diferencia notoria en el contenido de esta cláusula; las menciones a la Virgen se ven a lo largo de todo el siglo, así como las de la Santa Trinidad. No obstante, las invocaciones a la Virgen asociadas con su inmaculada concepción son más

(1616), ibídem, vol. 35, fols. 369-371. "Por la preciosa sangre de mi Señor Jesucristo y el cuerpo a la tierra del que fue formado", ibídem, vol. 115, fols. 469, 465-469. Otro ejemplo: Testamento de Don Diego de Baños y Sotomayor: "Mando mi ánima a Dios, Nuestro Señor, su divina Majestad, su precioso hijo con el tesoro infinito de su sangre y el cuerpo a la tierra" (1656), ibídem, vol. 53, fols. 681-686v; Testamento de Agustín de Pabón y Buendía: "Dios nuestro, su unigénito hijo, su preciosa sangre y su infinita piedad. El cuerpo mando a la tierra de la que fue formado" (1697), ibídem, vol. 113, fols. 268-277.

29 "Sea notorio a cuantos vieren cómo yo, Inés Biáfara..." (1610), AGN, Sección Notarías, Fondo Notaría 2, vol. 13, fols. 48-49. "Sepan cuantos [vieren] esta carta de testamento y postrimera voluntad, cómo yo, Doña María Blanco...” (1613), AGN, Sección Notarías, Fondo Notaría 1, vol. 33, fols. 359-361v. "Sepan cuantos [vieren] esta carta presente, cómo yo, Juan de Vera..." (1625), ibídem, vol. 39A, fols. 92v-94v. "Memoria que hizo Don diego, indio natural del pueblo de Teusacá, encomienda de Francisco Vanegas" (1626), ibídem, vol. 39B, fol. 623 . 
frecuentes a partir de la segunda mitad de la década del sesenta.

La segunda cláusula declaratoria se refiere a la confirmación de fe y religión de los testadores; en general, la mayoría reza: "Creyendo en todo lo que cree y confiesa la Santa Madre Iglesia de Roma" y "Creyendo en la Santísima Trinidad y en todo aquello que cree y confiesa la Santa Madre Iglesia de Roma". Dentro de aquellos que deciden nombrar a la Trinidad, algunos redactan de una forma más completa en qué consiste este dogma, por lo general, durante la primera mitad del siglo XVII, aunque sin descontar casos después de estas fechas. Como ejemplo excepcional, está uno de 1556, en el que se menciona también el dogma de la inmaculada concepción de María ${ }^{30}$ y otro, de 1694, que alude a la redención ${ }^{31}$.

Posteriormente, los testadores invocan a diferentes intercesores para su causa en el más allá; por lo general, es citada la Virgen María, Jesucristo y su méritos, los apóstoles y la corte celestial; aunque la más mencionada, en gran número de ocasiones la única, es la Virgen. Hubo cambios notables a través del tiempo en esta cláusula, a partir de la década del setenta, con un incremento en el número de atributos con los que es citada la Virgen y, durante las dos primeras décadas del siglo XVII, así como a partir del sesenta, el aumento en las advocaciones citadas por cada individuo.

En cuanto a la encomendación, puede verse que básicamente permanece igual todo el tiempo, utilizando los testadores la misma fórmula casi inalterada: "Mando mi ánima a Dios, Nuestro Señor, que la crió y redimió con su preciosa sangre y el cuerpo a la tierra de que fue formado"; en cinco casos, el lenguaje escogido fue un poco más adornado: "Mando mi ánima a Dios y le suplico que él, que la crió y redimió con su preciosa sangre, la quiera salvar y llevar a su santo reino cuando de este mundo fuera servido de me llevar" ${ }^{32}$; "El cuerpo a la tierra y el alma a mi Señor Jesucristo, que la redimió con su preciosa sangre"33; "Mando mi ánima a Dios, Nuestro Señor, su divina Majestad, su precioso hijo con el tesoro infinito de su sangre y el cuerpo a la tierra"34; "Mando mi ánima a Dios, Nuestro Señor, quien

\footnotetext{
${ }^{30}$ Testamento de Don Diego de Baños y Sotomayor: "Creo en la Santísima Trinidad, en la Encarnación de Nuestro Señor Jesucristo, en la Virgen Santa María, su bendita madre, en cuyas purísimas entrañas se encarnó y fue concebida [ella] sin mancha ni deuda de pecado original, así como todo lo demás en lo que cree y confiesa la Santa Iglesia de Roma" (1656), AGN, Sección Notarías, Fondo Notaría 1, vol. 53, fols. 681-686v.

${ }^{31}$ El dogma de la redención es el de la salvación de todos los hombres mediante el sacrificio de Jesús, es decir, su pasión y muerte. Testamento de Don Diego de Ospina y Maldonado: "Creo en la preciosa sangre, muerte y pasión y el cuerpo de Cristo" (1694), AGN, Sección Notarías, Fondo Notaría 1, vol. 112, fol. 113.

${ }^{32}$ Testamento de Doña Isabel de Sea (1603), ibídem, vol. 7, fols. 172-173v.

${ }^{33}$ Testamento de Doña María Blanco (1613), ibídem, vol. 33, fols. 359-361v.

${ }^{34}$ Testamento de Don Diego de Baños y Sotomayor (1656), ibídem, vol. 53, fols. 681-686v.
} 
la crió y redimió por el precio de su preciosa sangre, muerte y pasión, y el cuerpo mando a la tierra de la que fue formado"35; y "Dios Nuestro, su unigénito hijo, su preciosa sangre y su infinita piedad. El cuerpo mando la tierra de la que fue formado" ${ }^{36}$. Estos son casos aislados, en los cuales no prima ninguna relación de tiempo para explicar su diferencia con respecto a la generalidad, a no ser el deseo del testador de expresar así su devoción, podría decirse, más formalmente.

La segunda parte del documento se dedica a las disposiciones mundanas concernientes a la enumeración de los bienes del testador, el pago y el cobro de deudas y la repartición del remanente de los bienes entre los herederos forzosos y voluntarios, luego de sacar la parte destinada para las disposiciones funerarias. Aquí también podemos encontrar, en algunos casos, revelaciones, a veces extensas, del testador acerca de su vida personal, sus afectos, su familia, errores del pasado que desea enmendar, anotaciones sobre sus hijos o niños, a quienes adoptó y crió como a tales, comentarios sobre sobrinos u otros familiares, o sirvientes y esclavos, ya sea para agradecer por su compañía, cuidados y servicios o para hacer queja manifiesta de su ingratitud o sus calaveradas. Es esta parte no cuantificable del testamento la que en muchas ocasiones puede brindar al historiador luces acerca de innumerables aspectos de la vida cotidiana de los hombres de otros tiempos.

\section{Conclusiones}

El testamento del Antiguo Régimen nos revela una parte importante de la religiosidad popular en uno de sus aspectos fundamentales: la actitud del hombre ante la muerte. Hecho fundamental es la jerarquización de intereses entre el mundo terreno y el más allá deseado, donde el último prima y supedita las acciones del testador a este fin. Testar se convierte en un acto liberador en la medida que permite al hombre conciliar con la salvación eterna su disfrute de la vida terrena y de los bienes materiales en ella obtenidos. La Iglesia proporciona así la herramienta fundamental para alcanzarla mediante la renunciación y la contrición manifiestas en el cúmulo de obras pías y en los legados dispuestos en el testamento, que básicamente sirven para comprar la salvación ${ }^{37}$.

Asimismo, el de testar es un acto liberador, ya que, gracias a él, el otorgante revela en algunas ocasiones sus afectos, sus errores, sus actos de caridad y generosidad,

\footnotetext{
${ }^{35}$ Testamento de Pedro de Galavís (1675), ibídem, vol. 84, fols. 286-298v.

${ }^{36}$ Testamento de Agustín de Pabón y Buendía (1697), ibídem, vol. 113, fols. 268-277.

37 “ $¡ Y$ qué instrumento de poder para la iglesia! Esta afirma así su derecho (parcial) sobre las almas del Purgatorio como miembros de la Iglesia militante, haciendo avanzar el fuero eclesiástico con detrimento del fuero de Dios, a pesar de ser detentador de la justicia del más allá. Poder espiritual, pero también, por las buenas, como podrá verse, provecho financiero". Jacques Le Goff, El nacimiento del Purgatorio (Madrid: Taurus, 1981), 22.
} 
sus quejas, y también pone de manifiesto todo aquello que en vida no pudo llevar a efecto, como pagar deudas o expresar sentimientos hacia sus familiares, amigos, sirvientes y esclavos. Aunque el texto de los testamentos es más o menos estereotipado, nos permite adentrarnos en el mundo personal y cotidiano de la mayoría, en momentos históricos donde las autobiografías o los diarios no eran cosa común. Del mismo modo, las fórmulas devocionales nos dejan acercarnos a la mentalidad popular y al sistema de creencias imperante en las sociedades del Antiguo Régimen e igualmente nos permiten rastrear el grado de acatamiento, seguimiento y entendimiento en el ámbito religioso del sentimiento y la doctrina, al despejarnos el camino para seguir las prácticas públicas y privadas, individuales y colectivas.

Por otro lado, la proporción de hombres y mujeres dentro de la muestra trabajada mostró que testar era un derecho y un deber ejercido igualmente por ambos sexos aunque hay una pequeña mayoría masculina- casi todos casados. Esto también nos indica que, al menos en el plano económico, las mujeres contaban con una cierta autonomía, puesto que dispusieron de sus bienes, ya fueran conseguidos en vida con su esfuerzo, heredados o dotales, de forma autónoma, sin que mediara en sus decisiones la tutela paterna o conyugal. $\mathrm{Y}$ es posible notar que algunas mujeres ejercían oficios tales como el de estancieras, en virtud de poseer tierras, o el de tenderas, lo que les daba independencia económica.

Finalmente, la variedad de profesiones nos reafirma en la creencia de que el poder económico del testador no influyó en su religiosidad, simplemente aumentó las posibilidades de comprar su salvación a cambio de la gran cantidad de misas por su alma que podía pagar y el servicio fúnebre de primera que conseguía costear por medio de las limosnas que entregaba a la Iglesia. Aun aquellos con medios económicos limitados expresaron su fe y su religiosidad, aunque fuera en forma parcial.

\section{Bibliografía}

\section{Fuentes primarias}

Archivo General de la Nación, Bogotá, Colombia.

\section{Fuentes secundarias}

Ariès, Philippe. El hombre ante la muerte. Madrid: Taurus, 1984. 
Baeza, Diego de, Pbro. Sermones funerales catorce, y de ánimas de Purgatorio siete, 199 fols. Valladolid: Marcos Pérez, 1645.

Bosch de Centellas y Cardona, Baltasar. Prácticas de visitar a los enfermos y ayudar a bien morir. 4 ed. Madrid: Imprenta de Gregorio Hermosilla, 1722.

Buxó, María de Jesús i Rey, coord. La religiosidad popular. Vol. 2. Vida y muerte: la imaginación religiosa. Barcelona: Anthropos, 1989.

Geertz, Clifford. La interpretación de las culturas. Barcelona: Gedisa, 1995.

Le Goff, Jacques. El nacimiento del Purgatorio. Madrid: Taurus, 1981.

Fecha de recepción: 21 de abril de 2005.

Fecha de aceptación: 23 de agosto de 2005. 


\section{Anexo 1}

\section{Testamento de Isabel Venegas ${ }^{38}$}

En el nombre de Dios, nuestro Señor todo poderoso, amén.

Yo, Isabel Venegas, natural de esta ciudad de Santafé, hija legítima de Marco Venegas y de Leonor Rodríguez, difuntos, naturales que fueron de esta ciudad.

Estando enferma del cuerpo y sana de las voluntades y entendimiento, tal cual Dios, nuestro Señor, ha servido de darme, creyendo como firme y verdaderamente creo en el misterio de la Santísima Trinidad, Padre, Hijo y Espíritu Santo, tres personas distintas y un solo dios verdadero, y en todo lo demás que cree y confiesa nuestra santa madre Iglesia Católica Romana.

Temiéndome de la muerte, que es cosa natural, para cuyo trance toda criatura debe estar aprevenida y poniendo como desde luego pongo por mi intercesora a la soberana reina del Cielo, María Santísima, medre de Dios y señora nuestra, para que me alcance de su precioso hijo [el] perdón de mis pecados y lleve mi alma a ese reino para donde fue criado. Hago y ordeno este mi testamento, última y postrimera voluntad en la manera siguiente.

Primeramente encomiendo mi alma a Dios, nuestro Señor, que la crió y redimió con su preciosa sangre y el cuerpo a la tierra de que fue tomado.

Mando a las mandas forzosas de a dos reales cada uno, conque las aparto de mis bienes.

Quiero y es mi voluntad que cuando Dios, nuestro Señor, fuere servido de llevarme de esta presente vida, mi cuerpo sea amortajado con el hábito de nuestro seráfico San Francisco y [sea] enterrada en la iglesia de San Victorino, de donde soy feligresa, dejando como dejo la disposición de mi entierro a la de albacea y a que haga según la voluntad del que irá nombrado.

Ítem, declaro que fui casada de primer matrimonio según el orden de Nuestra Santa madre Iglesia, con Francisco Luis de Orejuelas Velazco, de esta dicha ciudad, de cuyo matrimonio no tuvimos hijo alguno.

Ítem, declaro que no llevé al poder del dicho mi marido dote alguna. Declárolo aquí para que conste.

Ítem, declaro que soy casada y velada de segundo matrimonio con Julio Francisco de Herrera, natural de la ciudad de Barcelona, en los reinos de España, de cuyo matrimonio no tenemos hijo alguno.

Ítem, declaro que no llevé al poder del dicho mi marido dote alguna y que todos los bienes que el susodicho tiene al presente los ha adquirido con su sudor y trabajo y si algunos de estos bienes me pertenecieren como ganaciales, quiero que de ellos se haga el costo de mi entierro, honras y cabo de año, y se me digan las misas que viera el dicho mi marido se me puedan decir.

Ítem, declaro por bienes míos los siguientes:

Primeramente, veinte patacones que me debe el maestro Miguel de Mesa, presbítero, más ha[ce] de dos años y medio que me pidió prestados por término de quince días. Mando se le cobren por bienes míos.

Ítem, declaro que tengo tres sayas, dos de seda y una de lana.

${ }^{38}$ AGN, Sección Notarías, Fondo Notaría 1, vol. 115, fols. 69-71. 
Ítem, declaro que no debo a persona alguna y que si apareciere alguna deuda, no la debo y así lo declaro para el descargo de mi conciencia.

Ítem, mando se le den a María de San Andrés, religiosa de velo blanco del convento de Nuestra Señora de la Concepción, de esta corte, mi hermana, diez patacones y la saya de lana, que tengo declaradas con más el baulito de Timaná con su cerradura y llave.

Ítem, declaro por mis bienes míos, dos mantellinas, la una de granillas con dos guarniciones de galón falso; y la otra, de bayeta de Castilla, amarilla, con dos vueltas de listón azul.

Quiero y es mi voluntad que la dicha mantellina de granilla, luego que yo fallezca, se le dé a Agustina de Guzmán, por ser pobre y haberme asistido a toda mi enfermedad.

Ítem, declaro por bienes míos dos casacas traídas; la una de lana, la otra de ormes.

$\mathrm{Y}$ del remanente de todos mis bienes, derechos y acciones que en cualesquiera manera me pertenezcan, dejo y nombro por mi único y universal heredero al dicho Julio Francisco de Herrera, mi marido, para que las halla, goce y herede con la bendición de Dios y la mía.

Ítem, mando se le den a Juan de Ramos, fajador de esta Real Audiencia, diez patacones para que, como quien asiste a la madre de Dios, de consolación, de dicha parroquia del Señor San Victorino, los aplique en el día de Jueves Santo para que se le encienda cera y la que sobrare le quede a la Madre de dios para que se le encienda los sábados al tiempo de su misa.

Para guardar y cumplir este mi testamento, mandas y legados y lo en él contenido, dejo y nombro por mi albacea testamentario al dicho Julio Francisco de Herrera, mi marido, para que entre en mis bienes y con ellos lo guarde, cumpla y ejecute según he declarado, y le prorrogo todo el termino necesario aunque sea pasado el año fatal del albaceasco.

$\mathrm{Y}$ revoco y anulo y doy por ningunos y de ningún valor ni efecto otras cualesquiera testamentos, codicilos o memorias testamentales que antes de este haya hecho y otorgado, y poderes que haya dado para testar judicial o extrajudicialmente, porque quiero no valgan ni hagan fe, en juicio ni fuera de él, salvo este que ahora otorgo, que quiero se guarde, cumpla y ejecute según como en él se contiene, como mi última y postrimera voluntad.

Hecho en la ciudad de Santafé a quince de marzo de mil y seiscientos noventa y nueve años, y la otorgante, que yo, escribano de su Majestad y público de número de esta ciudad, doy fe conozco, estando la susodicha al parecer en su entero y sano juicio lo otorgó y no firmó porque dijo no saber y a su ruego lo firmó uno de los testigos, que lo fueron llamados y togados, Francisco de la Cruz, Antonio Fuerte de Gracias, Buena Bentura Beltrán, Diego Martín Rodríguez y Jacinto Henríquez de Céspedes.

Al ruego de la otorgante, ante mí, Juan de Dios Ramos. 


\section{Anexo 2}

\section{Lista de testamentos analizados}

\begin{tabular}{|c|c|c|c|c|}
\hline 1600 & Testamento de Lázaro de Alfaro & Notaría 1 & volumen 24 , rollo 2 & fols. 934-941 \\
\hline 1603 & Testamento de Doña Isabel de Zea & Notaría 1 & volumen 7 , rollo 1 & fols. $172-173 v$ \\
\hline 1606 & Testamento de Antonio Rodríguez & Notaría 1 & volumen 29 & fols. $188-190$ \\
\hline 1609 & Testamento de Joan Macías Parra & Notaría 1 & volumen 31 & fols. $32-33 v$ \\
\hline 1610 & Testamento de Inés Biáfara & Notaría 2 & volumen 13 & fols. 48-49 \\
\hline 1610 & Testamento de Isabel Inyamundo & Notaría 2 & volumen 13 & fols. $78-79 v$ \\
\hline 1613 & Testamento de Doña María Blanco & Notaría 1 & volumen 33 & fols. $359-361 v$ \\
\hline 1613 & Testamento de Alonso García & Notaría 1 & volumen 32 & fols. $87-88 v$ \\
\hline 1615 & Testamento de Juana Páez & Notaría 1 & volumen 34 & fols. $424-428$ \\
\hline 1615 & Testamento de Pedro Antolínez & Notaría 1 & volumen 34 & sin fol. \\
\hline 1616 & Testamento de María Terranova & Notaría 2 & volumen 17 & fols. $98 v-99 v$ \\
\hline 1616 & Testamento de Micaela Rodríguez & Notaría 1 & volumen 34 & fols. $40-42$ \\
\hline 1616 & $\begin{array}{l}\text { Testamento de Pedro Mosquera de } \\
\text { Tamayo }\end{array}$ & Notaría 1 & volumen 35 & fols. $369-371$ \\
\hline 1617 & Testamento de Gonzalo Torres & Notaría 1 & volumen 35 & fols. $469-473$ \\
\hline 1617 & Testamento de Miguel de Castro & Notaría 1 & volumen 35 & fols. $119-120$ \\
\hline 1625 & Testamento de Juan de Vera & Notaría 1 & volumen $39 \mathrm{~A}$ & fols. $92 v-94 v$ \\
\hline 1626 & Testamento de Don Diego & Notaría 1 & volumen $39 \mathrm{~B}$ & fol. 623 \\
\hline 1633 & Testamento de Isabel de Espejo & Notaría 1 & volumen $41 \mathrm{~A}$ & sin fol. \\
\hline 1644 & $\begin{array}{l}\text { Testamento de Francisco Sánchez de } \\
\text { Oliva }\end{array}$ & Notaría 1 & volumen $46 \mathrm{~B}$ & fols. 99-103 \\
\hline 1645 & Testamento de Manuel Méndez & Notaría 1 & volumen 46B & fols. $79-82 v$ \\
\hline 1649 & Testamento de María Reales de Acosta & Notaría 1 & volumen $48 \mathrm{~A}$ & fols. $355-356$ \\
\hline 1650 & Testamento de Juliana Henríquez & Notaría 1 & volumen $48 \mathrm{~A}$ & fols. $442-443 v$ \\
\hline 1656 & $\begin{array}{l}\text { Testamento de Don Diego de Baños y } \\
\text { Sotomayor }\end{array}$ & Notaría 1 & volumen 53 & fols. $681-686 \mathrm{v}$ \\
\hline 1657 & Testamento de Melchor de Burgos & Notaría 1 & volumen 54 & fols. $86-87 v$ \\
\hline 1657 & Testamento de Ana María de San Joseph & Notaría 1 & volumen 54 & fols. $253-255 v$ \\
\hline 1659 & Testamento de Alonso Mejía Serrano & Notaría 1 , & volumen 59 & fols. $895-898$ \\
\hline 1661 & Testamento de Martín de Eussa & Notaría 1 & volumen 61 & fol. $133 y v$ \\
\hline 1666 & $\begin{array}{l}\text { Testamento de Doña Ana de Mendoza y } \\
\text { Escobar }\end{array}$ & Notaría 1 & volumen 68 & fols. $1-2$ \\
\hline 1666 & $\begin{array}{l}\text { Testamento de Doña Juana de Tapia y } \\
\text { Penagos }\end{array}$ & Notaría 1 & volumen 70 & fols. 14-18 \\
\hline 1668 & Testamento de Antonio de vega & Notaría 1 & volumen 73 & folios 405-407 \\
\hline 1668 & Testamento de Juana de Cárdenas & Notaría 1 & volumen 73 & fols. $492-494 v$ \\
\hline 1669 & Testamento de María de Torres & Notaría 1 & volumen 74 & fols. 351-352 \\
\hline 1672 & Testamento de Doña María Montaño & Notaría 1 & volumen 79 & fols. $519-520 v$ \\
\hline 1672 & Testamento de Pedro de Caravallo & Notaría 1 & volumen 79 & fols. 110-111 \\
\hline 1674 & Testamento de Mariana Ruiz Castañeda & Notaría 1 & volumen 84 & fols. 203-205 \\
\hline 1675 & $\begin{array}{l}\text { Testamento recíproco de Salvador Herrera } \\
\text { y Catalina Delgado }\end{array}$ & Notaría 1 & volumen 114 & fols. $479-481 v$ \\
\hline 1675 & Testamento de Melchor de los Reyes & Notaría 1 & volumen 84 & fols. $925-95 v$ \\
\hline 1675 & Testamento de Juan Álvarez de Abilez & Notaría 1 & volumen 84 & fols. $302-303 v$ \\
\hline 1675 & Testamento de Pedro de Galavís & Notaría 1 & volumen 84 & fols. $317-319 v$ \\
\hline 1681 & Testamento de Doña Catalina de Rioja & Notaría 1 & volumen 91 & fols. $93-94 v$ \\
\hline 1682 & Testamento de Francisco de Retuerta & Notaría 1 & volumen 92 & fols. $256-257$ \\
\hline 1682 & $\begin{array}{l}\text { Testamento de Don Guillermo Francisco } \\
\text { de Coclan }\end{array}$ & Notaría 1 & volumen 92 & fols. $128 y v$ \\
\hline 1688 & $\begin{array}{l}\text { Testamento de Pedro de Angulo y } \\
\text { Gamboa }\end{array}$ & Notaría 1 & volumen 110 & fols. $890-892$ \\
\hline 1690 & Testamento de Carlos Navarro & Notaría 1 & volumen 103 & fols. $95-97 v$ \\
\hline 1694 & Testamento de Juana Suárez & Notaría 1 & volumen 109 & fols. $109-110 \mathrm{v}$ \\
\hline 1694 & Testamento de Hipólito de Suazo & Notaría 1 & volumen 109 & fols. $191 v-193 v$ \\
\hline 1694 & Testamento de Don Diego de Ospina & Notaría 1 & volumen 112 & fol. 133 \\
\hline
\end{tabular}


Maldonado

1697 Testamento de Agustín de Pabón y Notaría 1

volumen 113

fols. 268-277

1698 Testamento de Gabriel Garrido Henríquez

Notaría 1

volumen 115

fols. 465-469

1699 Testamento de Isabel Venegas

Notaría 1

volumen 115

fols. 69-71 